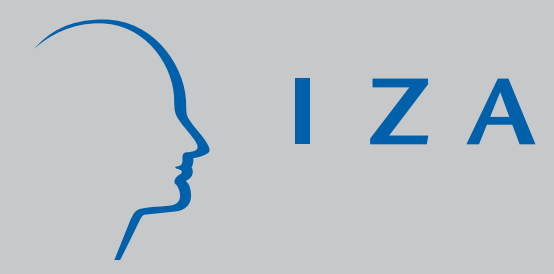

IZADP No. 3602

Consumers and the Brain Drain: Product Design and the Gains from Emigration

Peter Kunn

Carol McAusland

July 2008 


\title{
Consumers and the Brain Drain: Product Design and the Gains from Emigration
}

\author{
Peter Kuhn \\ University of California, Santa Barbara \\ and IZA \\ Carol McAusland \\ University of Maryland
}
Discussion Paper No. 3602
July 2008

IZA

P.O. Box 7240

53072 Bonn

Germany

Phone: +49-228-3894-0
Fax: +49-228-3894-180
E-mail: iza@iza.org

Any opinions expressed here are those of the author(s) and not those of IZA. Research published in this series may include views on policy, but the institute itself takes no institutional policy positions.

The Institute for the Study of Labor (IZA) in Bonn is a local and virtual international research center and a place of communication between science, politics and business. IZA is an independent nonprofit organization supported by Deutsche Post World Net. The center is associated with the University of Bonn and offers a stimulating research environment through its international network, workshops and conferences, data service, project support, research visits and doctoral program. IZA engages in (i) original and internationally competitive research in all fields of labor economics, (ii) development of policy concepts, and (iii) dissemination of research results and concepts to the interested public.

IZA Discussion Papers often represent preliminary work and are circulated to encourage discussion. Citation of such a paper should account for its provisional character. A revised version may be available directly from the author. 


\section{ABSTRACT \\ Consumers and the Brain Drain: Product Design and the Gains from Emigration*}

We consider the welfare effects of skilled worker emigration in a context where skilled labor plays a role in product design. We show such emigration can benefit the residents left behind, even when consumers' tastes exhibit a form of home bias. This is because emigration improves the design of goods designed by skilled emigrants but consumed in the sending country. In contrast to existing models of beneficial brain drain, our results do not require agglomeration economies, education-related externalities, remittances, return migration, or an emigration "lottery". Instead, they are driven purely by differences in market size that induce skilled emigrants to design better products abroad than at home.

JEL Classification: F22, J6, O34

Keywords: $\quad$ brain drain, international labor migration, product quality

Corresponding author:

Peter Kuhn

Department of Economics

University of California

Santa Barbara, CA 93106

USA

Email: pjkuhn@econ.ucsb.edu

\footnotetext{
* Kuhn received support from Industry Canada contract 5017079 on the International Mobility of Highly Skilled Workers during the early stages of this project. The authors acknowledge helpful comments from seminar participants at the University of California, Santa Barbara, University of Ottawa, Carleton University, and the International Symposium on Contemporary Labor Economics at Xiamen University. We are particularly grateful to two anonymous referees and the editor for very helpful comments on earlier drafts of this paper.
} 


\section{Introduction.}

Will a "brain drain" from a small or low-wage economy hurt or help residents remaining behind? The earliest economics literature on this question (e.g. Berry and Soligo 1969, Bhagwati and Hamada 1974) showed that remaining residents may be harmed by diminished opportunities to trade with differently-endowed agents. More recent contributions have identified a number of factors that could give rise to beneficial brain drain (BBD). These include increased incentives to acquire education in the sending country (Mountford 1997), remittances (e.g. Ozden and Schiff 2006), and added discipline on the sending country's tax authorities (Bucovetsky 2003).

In this paper we study another possible source of beneficial brain drain: the direct benefit to sending-country consumers that occurs when its brains move to an environment where they produce higher-quality goods. More specifically, we distinguish between two aspects of production-design and replication-and argue that skilled labor plays an important role in the former. Because improved design increases the value of every unit of a product distributed to consumers, its benefits accrue to all of its consumers, regardless of where they live. Thus sending-country consumers can gain by exporting their skilled workers if those workers design better products abroad than they would have had they stayed home.

Obvious examples of the effect we model might be scientists sent to a U.S. laboratory, actors sent to Hollywood, and programmers sent to Silicon Valley. If such individuals invent drugs, make movies, or write software of superior quality to what they would have produced in their home countries, then-because this higher quality applies to units of the good consumed in the home country as well-, the remaining residents of those countries may be better off. Slightly less obvious, but probably more important examples include contributions made by foreign-born managers and engineers to the quality of any good or service that is designed in the U.S. and consumed abroad. ${ }^{1}$ Of course, the level of marginal replication costs, the amount of home bias in tastes, and the strength of intellectual property rights (IPRs) in the sending and receiving countries will affect the magnitude of these gains in consumer welfare. We study these effects in this paper as well.

What factors might induce a sending country's brains to design higher-quality goods when employed abroad? While we can think of several-including agglomeration economies and a stronger IPR environment-in order to illustrate the distinct nature of the causal mechanisms studied here, our baseline model assumes identical production costs and full IPRs in both the sending and receiving countries. The welfare gains from brain drain come instead from market size and home-bias effects: if the foreign market is sufficiently larger than the sending country's, and if the product doesn't lose too much "in translation," the extra incentives to raise quality created by this larger market mean the (remaining residents of) the home country are better off allowing their skilled workers to emigrate.

\footnotetext{
${ }^{1}$ It is irrelevant to our basic argument whether the good is manufactured (i.e. replicated) in the immigrantsending or receiving country. In fact the gains to brain drain are enhanced when emigration creates manufacturing jobs in the migrant-sending country based on superior designs created by its expatriates.
} 


\section{Existing Literature}

As noted, the earliest economics literature on the "brain drain” (e.g. Berry and Soligo 1969), and indeed on international factor mobility in general (e.g. Jones, Coelho and Easton 1986), focused on induced changes in domestic factor prices and producer surplus in an undistorted "sending" economy. Although exceptions exist (for example the two-good, twofactor small open economy model in which factor rewards are independent of factor endowments, and the case of large countries whose terms of trade are advantageously affected by a factor outflow), in most of these models the reduction in opportunities to trade with differently-endowed agents makes remaining residents worse off after an outflow of skilled labor. $^{2}$

Since then, economists have identified a number of factors that accentuate the harm associated with a "brain drain". One such factor is a fiscal externality: in the presence of publicly-subsidized education and progressive taxation, the exodus of highly educated workers imposes a net fiscal loss on the sending country's remaining residents (Bhagwati and Hamada 1974). Also, in an endogenous growth context, some authors have argued that an outflow of educated workers can inflict substantial long run harm by reducing a country's growth rate (Miyagiwa 1991, Wong and Yip 1999). ${ }^{3}$

Over the same time period, however, the literature has identified a number of factors working in the opposite direction, generating what is sometimes referred to as "beneficial brain drain” (BBD). Probably the oldest such argument is the notion that emigration provides a social "safety valve" for unemployed skilled workers in less developed countries (see for example the discussion in Bhagwati and Rodriguez 1975). Two additional factors-by no means confined to skilled workers - are emigrants' cash remittances to the home country (e.g. Ozden and Schiff 2006), and the return migration of "brains" who have acquired new skills abroad (possibly at foreign taxpayers' expense). ${ }^{4}$ Less obviously, Stark, Helmenstein and Prskawetz (1997, 1998) have argued that the possibility of emigrating and earning a higher wage can raise incentives to acquire education in less-developed sending countries. If this effect is strong enough relative to the actual outflow of educated workers, the "sending" country's stock of skilled workers can of course rise. Extending this "emigration lottery" reasoning to an endogenous growth framework, Mountford (1997) has shown that the temporary possibility of skilled-worker emigration can "jump-start" an economy out of a poverty trap.

Most recently, Bucovetsky (2003) and Haupt and Janeba (2004) have considered the discipline that skilled emigration could impose on tax authorities in skilled-worker "sending" countries: human capital, once acquired, is sunk and therefore vulnerable to over-taxation by governments with limited commitment power. By constraining governments' abilities to tax

\footnotetext{
${ }^{2}$ Despite its age, the argument still figures prominently in contemporary policy discussions about international labor mobility (see for example Borjas 1995). Of course, nothing in the argument is specific to skilled labor: it pertains to any non-infinitesimal factor outflow that does not mirror the nation's factor endowment mix exactly. ${ }^{3}$ Introducing a skilled worker outflow into more traditional growth models (where growth occurs purely via either human or physical capital accumulation) has less dramatic negative long run effects (see, e.g. Rodriguez 1975).

${ }^{4}$ According to DeVoretz (2005), it is precisely this prospect of return migration that led China to relax its exit requirements in the early 1990s.
} 
human capital, the possibility of brain drain can induce those governments to act in their country's own long run interests, thus raising the long term level of human capital investment and per-capita income.

\section{The Model}

As noted, our vision of the production process for any good distinguishes two aspects: design and replication. The former determines a product's features, or the appeal to consumers of a single unit of the good, which we refer to as quality. The second involves replicating the prototype and distributing copies to consumers. While it seems natural to us that skilled workers are employed relatively intensively in the design phase rather than the production phase, this is not essential to our main result. To illustrate our main result most simply, our base-case model focuses on a single skilled worker at risk of emigration, whose only activity is product design. ${ }^{5}$ This "designer", scientist, artist, or "brain" produces a prototype good; examples of a prototype might be a musical recording, an insight into the laws of physics, or a malaria vaccine. To focus on essentials, our base case model assumes (as in Rosen 1981) that the prototype can be replicated costlessly. We briefly consider the effects of non-zero replication costs in Section 5.

Market willingness to pay for a single copy of the good depends on two product attributes: quality, $\rho$, and relevance, $t$; we discuss each attribute below. We assume individual inverse demand for a reproduction is given by $\operatorname{top}(q)$ where $p(q)$ is a decreasing function of quantity consumed per capita, $q$. We can interpret $p(q)$ as base inverse demand, i.e. as marginal willingness to pay for a unit of a good with $100 \%$ relevance and quality. Define $\varepsilon \equiv-\frac{1}{d p(q) / d q} \frac{p(q)}{q}$ as the elasticity of base demand. An interior solution to the profit maximization problem requires $\varepsilon$ to be decreasing in $q$, which we assume throughout the remainder of the paper.

The variable $\rho$ captures the intrinsic quality of a good; for example, if the good is a treatment for influenza, $\rho$ may index the speed with which the treatment reduces flu symptoms. We draw a distinction between quality and applicability, or relevance: ever since Armington (1969), several economists (e.g. Trefler 1995) have argued that consumers may inherently prefer locally produced goods. ${ }^{6}$ In the current paper we operationalize home bias via an iceberg "translation" cost $1-\tau$; we can think of $\tau$ as the fraction of a good's value that survives translation to a foreign market. Recalling terminology introduced above, let $t^{i j}$

\footnotetext{
${ }^{5}$ The remaining residents of the designer's home country can be thought of either as unskilled workers who produce a numeraire good at constant unit cost, or as other designers who produce prototypes that do not compete with the potential migrant's prototype. Either way, the incomes of these remaining residents will not be affected by whether the migrant stays or leaves, which allows us to focus on the new (consumption-related) aspects of our model here. Modelling the migration of multiple noncompeting brains would of course be straightforward; modelling competition between migrating and local brains (in both the sending and receiving countries) would require a differentiated products framework with endogenous quality choice. We have also studied a version of the model in which unskilled workers derive their incomes by making copies of prototypes. None of these changes affect the basic point of our paper, so we have elected to illustrate that point in the simplest possible way.

${ }^{6}$ Empirical studies tend to find strong evidence of home bias in consumption. For example, Whalley and Xin (2006) show home bias can account for over $90 \%$ of the measured border effect in US-Canada trade.
} 
measure the relevance to consumers in market $i$ of a good developed in market $j$; with iceberg translation costs, $t^{S R}=t^{R S}=\tau \in[0,1]$ while $t^{S S}=t^{R R}=1$. One way to interpret $\tau \rho$ is as the net premium for imported, or translated, goods. We treat $\tau$ as a parameter outside the designer's and government's control, however we acknowledge that $\tau$ will vary with the type of good considered: for instrumental music $\tau$ may be near unity; the $\tau$ associated with comedy is often remarked to be close to zero. ${ }^{7}$

If emigration is legal, the designer faces a two-stage problem. First she must decide where to live and work, and second she must decide what quality prototype to produce and how to price it to each market. As usual, we begin with the second stage.

\section{1 Stage Two: Profit Maximization}

We simplify the world into two countries: Source $(S)$ and Recipient $(R)$. Let $N^{i}$ be the number of consumers in country $i \in\{S, R\}$. Define $\pi^{i}=\max _{q} p^{i}(q) q$ as the designer's maximized per capita base profits from market $i$, and $q^{i}=\operatorname{argmax}_{q} p^{i}(q) q$ as her optimal per capita deliveries to this market. ${ }^{8}$ Note that our inverse demand functions are indexed by country (i); this allows per-capita income differences to enter our model with higher income assumed to shift the inverse demand curve upwards. In this section we assume that both Source and Recipient provide full legal protection of intellectual property rights (IPRs). Thus the designer is an uncontested monopolist in both markets, and will choose $q^{i}$ such that $\varepsilon=1$ in each market. Using these definitions, we can rewrite the designer's total profits from market $i$ when residing in country $j$ as $N^{i} t^{i j} \rho \pi^{i}$. Further, the designer can treat $\pi^{S}$ and $\pi^{R}$ as parameters when solving her investment and location problems.

Improving the quality of the prototype comes at a price. The brain may hire complementary inputs (a scientist outfitting a better lab, or an industrial engineer hiring more qualified colleagues and assistants), acquire additional human capital (voice lessons for an opera singer, a post doc for a biologist or M.B.A. for a manager), or simply put in more effort (work more intensely or for longer hours). We will refer to any such actions as investments. Let $c(\rho)$ measure the total cost of producing a prototype of quality $\rho$. To make things simple we assume $c(\rho)=\rho^{1+\Psi / \Psi}$; convexity requires $\Psi>0$.

The designer's optimal investment depends on the effective size of her global market. Define $X^{i}=N^{i} \pi^{i}$ as effective market size in country $i$. When the designer remains in Recipient her effective global market size is $M^{R}=X^{R}+\tau X^{S}$; when she resides in Source it is $M^{S}=\tau X^{R}+X^{S}$. Thus when the designer lives in country $j$ she chooses $\rho$ to

$$
\max _{\rho} \rho M^{j}-c(\rho)
$$

The cost function's convexity ensures the second order conditions for an interior maximum hold; rearranging the first order condition $M^{j}=c^{\prime}(\rho)$ yields

\footnotetext{
${ }^{7}$ Importantly, the home bias in our paper refers to the designer's current location, not his/her country of birth; thus we assume that, for example, Indian consumers treat goods produced by Indian expatriates in the United States similarly to goods produced by other Americans. In part, this is based on a prevalent notion in the business literature that close contact (in our case living in the same country and culture) with consumers is essential to producing innovations that customers like (see for example Ulwick 2002).

${ }^{8}$ Because $\varepsilon$ is decreasing in $q$, base profits $p^{i}(q) q$ are locally concave at $q^{i}$ and $q^{i}$ is unique.
} 


$$
\rho\left(M^{j}\right)=\xi M^{j^{\Psi}}
$$

where $\xi \equiv\left(\frac{\Psi}{1+\Psi}\right)^{\Psi}>0$. Differentiating gives $d \rho / d M^{j}=\Psi \rho / M^{j}>0$, indicating quality is increasing in market size. This is as one would expect: when the designer can collect a quality price premium from more consumers, she invests in creating a higher quality product. We interpret increases in $\rho$ as quality creation; any action by the designer or a government that increases the size of the designer's effective market will in turn have a quality creation effect. Not surprisingly, the elasticity of product quality with respect to market size depends on the curvature of the design cost function: $\frac{d \rho}{d M^{j}} \frac{M^{j}}{\rho}=\Psi$, so the more convex design costs are, the more elastic quality is to market size.

\subsection{Stage One: Emigration}

We assume zero relocation costs. Since the designer earns more when $M$ is larger, she will move to wherever her residency confers the largest global base market. For $\tau<1$, whether $M^{S}<M^{R}$ depends only on relative populations and base profits. Assuming the designer stays home when indifferent, we obtain the following lemma.

Lemma 1. If translation costs are non-zero (i.e. $\tau<1$ ), the designer emigrates if and only if $X^{S}$ $<X^{R}$.

If both countries have the same individual inverse demand curves (for example because their per capita income levels and tastes are the same), Lemma 1 implies that the designer optimally locates herself in the country with the largest population for any non-zero level of translation costs. Of course, the designer might optimally choose a country with smaller population if its consumers were sufficiently richer than the other country.

The designer relocates only if Recipient's market is larger than Source's. Once immersed in the Recipient market, the designer responds to the increased returns on her investment, producing a higher quality prototype.

Proposition 1: Voluntary emigration induces quality creation.

\section{Proof:}

By Lemma 1 the designer emigrates voluntarily if and only if $\tau<1$ and $X^{R}>X^{S}$, thus $M^{R}>M^{S}$. Since $d \rho / d M>0$ then $\rho\left(M^{R}\right)>\rho\left(M^{S}\right)$ and so emigration leads to higher quality goods. 


\section{Beneficial Brain Drain}

We now turn our attention to conditions under which brain drain is beneficial to the parties involved. In order to minimize the number of cases that must be described, we restrict our attention in the remainder of the paper to cases in which the designer will emigrate if allowed, i.e. in which $X^{R}>X^{S}$.

A simple revealed preference argument confirms that the designer benefits from voluntary migration. Whether consumers gain depends on the rate of quality creation versus translation costs.

Lemma 2: Consumers in country $i$ are better off when the designer voluntarily emigrates if and only if

$$
t^{i S} \rho\left(M^{S}\right)<t^{i R} \rho\left(M^{R}\right) .
$$

Proof: Let $C S^{i j}=N^{i} t^{i j} \rho \Phi^{i}$ measure consumer surplus in country $i$ when the designer resides in country $j$, where

$$
\Phi^{i} \equiv \int_{0}^{q^{i}} p(q) d q-p\left(q^{i}\right) q^{i}
$$

is "base" consumer surplus per capita, i.e. consumer surplus associated with qualityunadjusted goods, when $q^{i}$ units are sold per capita in country $i$. As $N^{i}$ and $\Phi^{i}$ are independent of $\rho$, $\mathrm{CS}^{i S}<C S^{i R}$ if and only if (2).

Proposition 2: Recipient consumers gain from voluntary migration.

Proof: For $i=R, \rho\left(M^{R}\right)>\tau \rho\left(M^{S}\right)$ is guaranteed by $\tau<1$ and Proposition 1 .

Proposition 2 confirms that the designer's emigration unambiguously benefits consumers in the Recipient country. Firstly, they benefit from the quality creation stemming from the designer accessing a larger market. Secondly, migration induces quality diversion: the designer's work now caters more to the tastes of Recipient consumers and less to Source's consumers.

Quality creation benefits Source's consumers while quality diversion hurts them. Evaluating (2) for Source's consumers puts this tradeoff in mathematical terms: Source's consumers are better off whenever the rate of quality creation, $\left[\rho\left(M^{R}\right)-\rho\left(M^{S}\right)\right] / \rho\left(M^{R}\right)$, dominates the rate of quality diversion, $1-\tau$.

Proposition 3: There exists $\bar{\tau} \in(0,1)$ such that the designer's emigration benefits Source's consumers for $\tau \in(\bar{\tau}, 1)$ if and only if the Source market is sufficiently small compared to Recipient's and design costs are sufficiently elastic, i.e.

$$
\frac{X^{R}-X^{S}}{X^{R}+X^{S}}>\frac{1}{\Psi}
$$


if instead (3) is violated then Brain Drain is harmful to Source's consumers for any $\tau<1$.

\section{Proof:}

Define $\bar{\tau}$ as the value of $\tau \in(0,1)$ at which the difference between the rates of quality creation and diversion,

$$
\frac{\rho\left(M^{R}\right)-\rho\left(M^{S}\right)}{\rho\left(M^{R}\right)}-[1-\tau]
$$

is zero. Since (4) equals zero at $\tau=1$ and is negative at $\tau=0$, such a $\bar{\tau}$ exists if and only if $\frac{d}{d \tau}\left[\frac{\rho\left(M^{R}\right)-\rho\left(M^{S}\right)}{\rho\left(M^{R}\right)}-[1-\tau]\right]$ is negative when evaluated at $\tau=1$. Using $\rho\left(M^{j}\right)=\xi M^{j \Psi}$ and defining $\alpha \equiv X^{S} / X^{R}<1$ allows us to write (4) as $\tau-\left[\frac{\tau+\alpha}{1+\tau \alpha}\right]^{\Psi}$.

Differentiating with respect to $\tau$ and evaluating at $\tau=1$ gives $\left.\frac{d}{d \tau}\left[\frac{\rho\left(M^{R}\right)-\rho\left(M^{S}\right)}{\rho\left(M^{R}\right)}-[1-\tau]\right]\right|_{\tau=1}=1-\Psi\left[\frac{1-\alpha}{1+\alpha}\right]$, which is negative only when (3) holds.

Corollary: If (3) holds then there exists a non-empty interval of translation rates, $\tau$, under which voluntary emigration raises the welfare of the migrant as well as consumers in both countries. ${ }^{9}$

Figure 1 depicts the creation-diversion trade off from the perspective of Source consumers. At the extremes, when translation losses are complete (i.e. $\tau=0$ ), quality creation is irrelevant to Source's consumers since none of it survives translation. At the other extreme, if $\tau$ is instead unity, any additional quality creation would be perfectly useful to Source's consumers; however, because $M^{S}$ and $M^{R}$ would be identical, emigration would leave $\rho$ unchanged. But, if $\tau$ has an intermediate value, then voluntary emigration prompts additional investment and some of that quality improvement survives translation. If $\tau$ is not too small, the net value of the designer's product will rise for Source's consumers, rendering brain drain beneficial. ${ }^{10}$

\footnotetext{
${ }^{9}$ Our model implicitly assumes the migrant has monopoly power. In a more general setting migrants' residency and investment choices would impact competing suppliers, as in, for example, a differentiated goods framework. The impact of quality creation and diversion on competing suppliers in the Recipient market would be straightforward: increased competition from immigrants would hurt them. Competitors remaining behind in Source may also be hurt. If $\tau \rho^{R}>\rho^{S}$ then, even though the Source market is supplied by fewer residents, emigration would nevertheless raise effective supply to the Source market, hurting (non-migrating) Source producers as well.

${ }^{10}$ We characterize $q$ as a final good and the beneficiaries of knowledge creation as consumers. However reframing $q$ as an intermediate input, one which unskilled migrants employ to raise their own productivity, would be straightforward. Aside from accounting for feedback effects on unskilled wages (accompanying the
} 


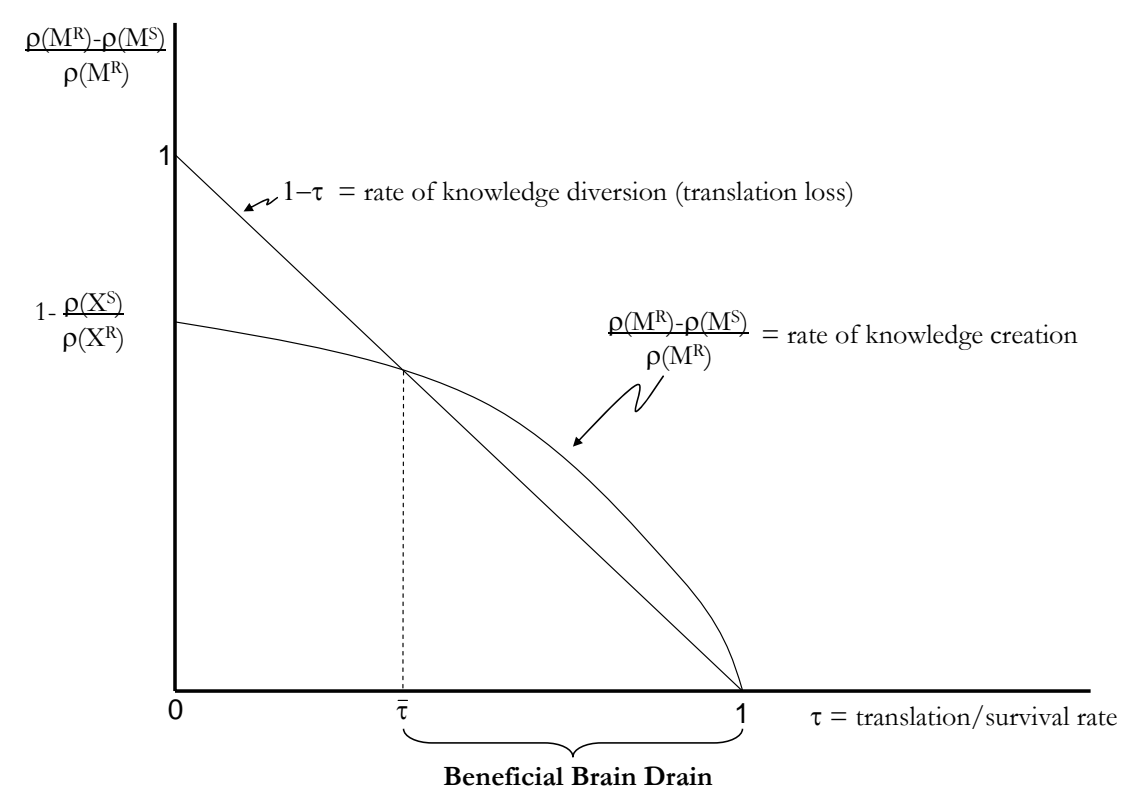

Figure 1: knowledge creation versus knowledge diversion

Whether (3) holds depends on a number of factors. Firstly, since $\frac{X^{R}-X^{S}}{X^{R}+X^{S}}<1, \Psi>1$ is a necessary condition for BBD. Recalling (2), $\Psi>1$ equates to requiring quality be elastic with respect to market size: since quality creation is the only channel through with brain drain helps Source consumers in our model, quality creation must be sufficiently responsive to rewards in order for brain drain to be beneficial.

Secondly, because $\rho$ is increasing in $M$, the larger the difference between $M^{R}$ and $M^{S}$ the greater the quality creation effect accompanying emigration. Accordingly, the larger the gap between $X^{R}$ and $X^{S}$ for a given $\tau$, the more likely Source is to gain from brain drain. The following proposition formalizes this result.

Proposition 4. The interval of survival rates $(\bar{\tau}, 1)$ over which Brain Drain is beneficial to Source's consumers is larger when Source's effective market size $X^{S}$ is small relative to Recipient's, $X^{R}$. Specifically, $\frac{d \bar{\tau}}{d \alpha}>0$ where $\alpha \equiv \frac{X^{s}}{X^{R}}$.

Proof: Holding $\tau$ constant, raising $\alpha$ lowers the rate of quality creation:

$\frac{d}{d \alpha}\left[\frac{\rho\left(M^{R}\right)-\rho\left(M^{s}\right)}{\rho\left(M^{R}\right)}\right]=-\Psi\left[\frac{\alpha+\tau}{1+\alpha \tau}\right]^{\Psi-1} \frac{1-\tau^{2}}{(1+\alpha \tau)^{2}}<0$. Thus an increase in $\alpha$ shifts the quality creation curve down, raising $\bar{\tau}$ non-skilled migrants if intermediate goods improve in quality enough to compensate for the loss in relevance. 
In short, relative size matters. The smaller the Source country is relative to the recipient economy, the larger the range of translation costs at which brain drain is mutually beneficial. This suggests that brain drain is more likely to beneficial to small countries than to medium sized countries: if a country's native market is large enough to induce some investment-but not large enough to drown out the siren call of large consumer markets like the U.S. - brain drain is more likely to harm consumers left behind.

\section{Extensions}

\subsection{Endogenous IPRs}

Market size is critical in our model: differences in effective market size drive brains to migrate and are ultimately responsible for quality creation. Some of the factors determining effective market size, e.g. the size and income level of the native population-the latter being a determinant of base demand-, are outside the control of policymakers, at least in the short run. However, since the goods in question can be reproduced at zero or low cost (see below), then $\pi^{S}$ also depends on de jure and de facto rules governing intellectual property rights (IPRs).

Strong IPRs provide incentives for innovation, with benefits for anyone who ultimately consumes or uses the innovation. IPRs are costly though; they grant patent holders market power, generally inducing deadweight loss. ${ }^{11}$ Brain drain affects the innovationdistribution tradeoff for a Source country. Strengthening Source's IPRs raises $\pi^{\mathrm{S}}$ and so expands the designer's effective market regardless of where she actually lives and works (provided $\tau>0$ ). However, the rate at which her market expands is residency dependent: if the designer emigrates, strong Source IPRs contribute only $\tau$ as much to the designer's innovation incentives than if she had stayed home. In contrast, the costs for Source are the same: stricter Source IPRs translate to higher prices for Source consumers. Consequently, we anticipate that Source countries will set weaker policies when their exits are open rather than closed. ${ }^{12}$ This simple observation raises obvious concerns about endogeneity in empirical tests of the link between intellectual property rights and factor migration: do weak IPRs in small, developing countries drive human capital abroad, or are they the instead the result? ${ }^{13}$

\subsection{Positive reproduction costs}

In our baseline model we assume zero reproduction costs. It is straightforward to show that introducing a constant per-unit reproduction cost $b$ leaves our results unchanged. With reproduction costs, the designer's optimal per capita delivery to market $i$ is $\overline{q^{i}}=$ $\operatorname{argmax}_{q}\left[p^{i}(q)-b\right] q$, the corresponding maximized per capita base profit is $\overline{\pi^{i}}=\max _{q}\left[p^{i}(q)\right.$ -

\footnotetext{
${ }^{11}$ Grossman and Lai (2004) analyze many of the factors influencing IPR choice in an international context; they do not consider emigration.

${ }^{12}$ Kuhn and McAusland (2006) offer a mathematical version of these arguments and also show that BBD is even more likely when Source's IPRs are endogenous. By weakening IPRs Source can raise base consumer surplus, allowing Source's consumers to reap a greater share of the benefits from quality creation.

${ }^{13}$ Our thanks to an anonymous referee for this observation.
} 
b] $q$ and effective market size is $\bar{X}^{i}=N^{i} \bar{\pi}^{i}$. Aside from the change in symbols, the remainder of the analysis in sections 3 and 4 proceeds as before. We note that, since $\overline{\pi^{i}}$ is decreasing in $b$, higher reproduction costs erode effective market size, with obvious implications for incentives to invest in quality.

\subsection{Endogenous reproduction costs}

Product quality is only one output from research and development; skilled labor is also used to design more cost efficient production processes. In this subsection we briefly address whether brain drain might benefit Source consumers when the investment choice concerns expending resources so as to lower marginal reproduction costs (rather than to improve quality). For simplicity, in what follows we treat quality $\rho$ as exogenous and assume the demand functions are identical across countries: $p(\cdot)=p^{*}(\cdot)$. Let $d(b)$ denote investment costs necessary to achieve marginal reproduction cost $b$; assume $d$ is positive, decreasing, and convex. Per capita base profits will be $\pi(b)=\max _{q}[p(q)-b] q$; denote the brain's total profits by $\Pi(b) \equiv \rho t^{S j} N^{S} \pi(b)+\rho t^{R j} N^{R} \pi(b)-d(b)$.

We assume the second order conditions for an interior maximum hold; the brain's optimal choice of $b$ solves $\rho A^{j} \pi^{\prime}(b)-d^{\prime}(b)=0$ where $A^{j} \equiv t^{S j} N^{S}+t^{R j} N^{R}$ is the size of the relevanceadjusted population when the brain resides in country $j$. Since $\pi$ and $d$ are each independent of population size and residency, by the envelope theorem

$\operatorname{sgn}\left[\frac{d b}{d A}\right]=\operatorname{sgn}\left[\frac{\partial \Pi}{\partial A}\right]=\operatorname{sgn}\left[\rho \pi^{\prime}(b)\right]$.

As $\pi^{\prime}(b)=-q^{i}<0$, an increase in effective population, $A$, induces the brain to invest in lowering reproduction costs. The Brain will emigrate only if $A^{R}>A^{S},{ }^{14}$ thus brain drain has a costreducing effect. Moreover, because some of this cost reduction will be passed along to consumers, emigration indirectly lowers base prices and raises base consumer surplus. Whether Source consumers are better off is ambiguous. Although base consumer surplus rises, brain drain still diverts quality away from Source consumers. Which dominates-lower costs versus less relevant products - depends on how elastic the function $d$ is, how much larger Recipient is compared to Source, and how much relevance survives translation.

In sum, the effects of migration on brains' investments in reducing replication costs, and correspondingly on both home and host country consumers, are conceptually quite similar to the effects of migration on investments to improve product quality. What is critical in both cases is the "public" nature of these investments, emphasized by Rosen both in the context of entertainment (1981) and management of firms (1982): in our formulation, both a better product design, and a cheaper method of producing copies of a given design, apply to all copies of a good that are produced. It is this feature that comprises what to our knowledge is a new and potentially important channel via which skilled worker migration may affect the welfare of remaining residents in the sending country.

\footnotetext{
${ }^{14}$ Since we have assumed $\pi^{R}=\pi^{S}$ in this subsection, voluntary migration requires $N^{R}>N^{S}$.
} 


\section{Discussion}

It is often claimed that a large and increasing share of global economic activity involves the production and exchange of "knowledge goods", defined as goods whose quality per unit is determined by an input of highly skilled labor, but which can be copied at zero or low marginal cost. In the late twentieth century, the production of such goods was highly concentrated in a single country with a large domestic market (in most cases the United States). ${ }^{15}$ In addition, a significant share of these goods was produced by immigrants to that country. ${ }^{16}$ While the exodus of talented "brains" to larger, richer economies is sometimes bemoaned in sending countries, this paper shows that, under quite general conditions, the above pattern could be in the interests of the migrating brains, the remaining residents of the nations that send them, and consumers in the host country. The remaining residents benefit because "their" brains produce products of higher quality (such as more effective medicines, more entertaining movies, or more powerful software) abroad than if they had remained at home.

Some noteworthy features of our model include the following. First, beneficial brain drain "BBD" is possible even when (a) the sending country places no welfare weight on the utility of its expatriates, (b) goods are less culturally relevant to the source market when produced abroad, that is, when demands exhibit home bias, or "translation loss", and (c) both sending and receiving countries fully protect brains' intellectual property rights in a national treatment framework. Second, while we acknowledge that agglomeration economies may be important in explaining the location of many industries (e.g. Rivera-Batiz and Romer 1991) such external economies are absent from our model. Instead, international specializationvia the migration of "knowledge" producers to a single country-can result simply from differences in domestic market size and home bias in tastes.

Third, the level of home bias in consumers' tastes has interesting effects in our model. If we think of our parameter $\tau$ (the fraction of a good's value that survives export to another country) as rising over time due to declines in international transportation and communications costs, then our model predicts that source countries' benefits from brain drain will be minimal when international communication is poor, and will then rise as the ability of product designers in one country to serve consumers in another rises. It is only in the limiting case of zero 'home bias' $(\tau=1)$-where 'brains' can serve the world's consumers equally well from any location - that better international communication eliminates the gains to consumers in a small or poor country from sending their brains abroad.

\footnotetext{
${ }^{15}$ Using purchasing power parity measures of R\&D activity, Dougherty et al (2003) find that expenditures in the US exceeded the combined expenditures of the next four leading research nations, Germany, Japan, France and UK. In 2000, 34.3\% of Triadic Patent Families (defined by the OECD as "patents taken out at the European Patent Office (EPO), the Japanese Patent Office (JPO) and the US Patent \& Trademark Office ( USPTO) that share one or more priorities”) were taken out by American residents. The comparable proportions for residents of Japan and the EU are 26.9 and 31.4 (Source: OECD, Patent Database, September 2004.) The international predominance of the United States as a source of commercial popular culture is well known.

${ }^{16}$ In addition to entertainers, this of course includes scientists and engineers working in U.S. firms and universities. Nearly one in five scientists and engineers in the United States is an immigrant; 51 percent of US doctorates in engineering are currently awarded to foreigners (Zakaria 2005).
} 
Fourth, while our baseline model assumes zero reproduction costs, our results do not require this. Moreover, we argue that brain drain may benefit consumers in the sending country when reproduction costs are endogenous, even when quality is exogenous. If migrating brains use their talents to reduce reproduction costs instead, source countries may gain from brain drain through lower base prices. In fact, in our framework, design investments by expatriate brains of the "process innovation" type (those that reduce marginal reproduction costs) operate in much the same way as design decisions affecting the product's appeal to consumers; the key is that innovations created by brains affect all copies of the goods they are involved in producing, whether by raising quality or reducing unit cost.

Finally, our results have implications for policies affecting "brain drain" in small or poor countries that have not, to our knowledge, been noted before. For example, skilledemigrant-sending countries may want to refine their policies (or at least their discussion of brain drain) by distinguishing emigrants according to the types of goods they produce. Thus, for example, our model would not apply to the emigration of a physician who spends all of her time treating patients; while she is skilled she produces a purely private good rather than a prototype that can be replicated at low marginal cost. Thus her emigration may be more likely to hurt the remaining residents of her country than the emigration of a physician primarily engaged in research on new treatments and medicines (whether improving their quality or reducing their marginal reproduction costs), to which our analysis does apply.

In sum, this paper shows that brain drain may benefit the remaining residents of a country by improving the quality of the goods they consume, or the cost (and therefore price) of replicating a unit of the goods they consume. To the best of our knowledge, this effect has not yet been noted in the economics literature. We hope the present paper encourages others to explore additional feedback effects of international migration on consumers in both the sending and receiving countries. 


\section{References}

Armington, Paul S. "A Theory of Demand for Products Distinguished by Place of Production." International Monetary Fund Staff Papers March 1969, 16(1): 159-78.

Berry, R. and R. Soligo, "Some welfare aspects of international migration" Journal of Political Economy 77 (1969).

Bhagwati, J. and K. Hamada, "The brain drain, international integration of markets for professionals and unemployment: A theoretical analysis". Journal of Development Economics 1(1) (1974)

Bhagwati, J. and C. Rodriguez. "Welfare-Theoretical Analyses of the Brain Drain” Journal of Development Economics 2 (1975) 195-221.

Borjas, George J. "The Economic Benefits From Immigration," Journal of Economic Perspectives, 1995, 9(2), 3-22.

Bucovetsky, S. "Efficient Migration and Income Tax Competition" Journal of Public Economic Theory. April 2003; 5(2): 249-78

DeVoretz, D. “International Mobility of Highly Skilled Workers: Quo Vadis?” Mimeo, Simon Fraser University, 2005.

Dougherty, Sean M., Robert Inklaar, Robert H. McGuckin, and Bart Van Ark. "Internationalization and the Changing Structure of Business R\&D: Recent Trends and Measurement Implications" mimeo 2003, The Conference Board and Growth and Development Center of the University of Groningen.

Grossman, Gene M. and Edwin L.-C. Lai. "International Protection of Intellectual Property” American Economic Review (December 2004): 1635-1653.

Haupt, A. and E. Janeba. "Education, Redistribution, and the Threat of Brain Drain”. NBER working paper no 10618, June 2004.

Jones, R.W., I. Coelho and S. Easton, 1986, The theory of international factor flows: The basic model, Journal of International Economics 20, 313-327.

Kuhn, Peter J. and Carol McAusland. 2006. "The International Migration of Knowledge Workers: When Is Brain Drain Beneficial?” IZA Working Paper \#2493.

Miyagiwa, Kaz. "Scale Economies in Education and the Brain Drain Problem” International Economic Review. August 1991; 32(3): 743-59

Mountford, A. (1997) "Can a Brain Drain be Good for Growth in the Source Country?" Journal of Development Economics 53, 287-303. 
Ozden, Caglar and Maurice Schiff, eds. International Migration, Remittances, and the Brain Drain Washington, D.C.: World Bank; Houndmills, U.K. and New York: Palgrave Macmillan, 2006.

Rivera-Batiz, Luis A., and Paul M. Romer. "Economic Integration and Endogenous Growth” Quarterly Journal of Economics 106 (2) (May 1991): 531-555.

Rodriguez, C. (1975) “On the Welfare Aspects of International Migration” Journal of Political Economy 1975.

Rosen, Sherwin. (1981) "The Economics of Superstars" American Economic Review Vol. 71, No. 5. (Dec.1981), pp. 845-858

Rosen, Sherwin. “Authority, Control, and the Distribution of Earnings” Bell Journal of Economics13(2) (Autumn 1982): 311-23.

Stark, O., C. Helmenstein and A. Prskawetz (1997) “A Brain Drain with Brain Gain” Economics Letters 55, 227-234.

Stark, O., C. Helmenstein and A. Prskawetz (1998) "Human Capital Depletion, Human Capital Formation, and Migration: A Blessing or a Curse?” Economics Letters 60, 363-367.

Trefler, Daniel. 1995. “The Case of the Missing Trade and other Mysteries,” American Economic Review 85(5): 1029-1046.

Ulwick, Anthony W. “Turn Customer Input into Innovation” Harvard Business Review 80(1) (January 2002): 91-97

Whalley, John and Xian Xin. 2006. "Home and Regional Biases and Border Effects in Armington Type Models,” NBER Working Paper No. 12439.

Wong, Kar-yiu and Chong Kee Yip. “Education, economic growth, and brain drain” Journal of Economic Dynamics and Control 23 (1999) 699-726.

Zakaria, Fareed. "The Wealth of Yet More Nations”. Review of T. Friedman, The World is Flat: A Brief History of the Twenty-First Century, New York Times Book Review, May 1, 2005, pp. 10-11. 